\title{
Underlying Dimensions of the Physical Educators' Judgments about Inclusion Instrument: Brazilian-Version
}

\author{
Samuel R. Hodge ${ }^{1, *}$, Paulo José Barbosa Gutierres Filho ${ }^{2}$, Justin A. Haegele ${ }^{3} \&$ Francis M. Kozub \\ ${ }^{1}$ Department of Human Sciences, The Ohio State University, Columbus, OH. 43210-1224, USA \\ ${ }^{2}$ Faculdade de Educação Física, Universidade de Brasília, Asa Norte, DF, Brasil \\ ${ }^{3}$ Department of Human Movement Sciences, Old Dominion University, Norfolk, VA. 23529, USA \\ ${ }^{4}$ Department of Physical Education and Sport, The College at Brockport, New York 14420, USA \\ *Correspondence: Department of Human Sciences, The Ohio State University, A-254 PAES Building, 305 West 17th \\ Avenue, Columbus, OH. 43210-1224, USA. Tel: 1-614-292-8364. E-mail: hodge.14@osu.edu
}

Received: August 25, $2015 \quad$ Accepted: October 17, $2015 \quad$ Online Published: November 1, 2015

doi:10.5430/jct.v4n2p96 URL: http://dx.doi.org/10.5430/jct.v4n2p96

\begin{abstract}
Background/Objective: The available information pertaining to the attitudes of Brazilian physical education teachers about teaching students with disabilities is limited in the extant literature base. Rationally, however, scholars argue that determining, analyzing, and theorizing about the attitudes of physical education teachers is important in the preparation and professional development of these teachers. It is therefore important to extend the research base using valid and reliable measures regarding teachers' attitudes about inclusion and teaching students with various disabilities. Purpose: The purpose of this study was to examine the underlying dimensions of the Physical Educators' Judgments about Inclusion (PEJI) scale following translation procedures that converted the existing measure to Portuguese. The PEJI was designed to analyze teachers' attitudes about inclusion and teaching students with various disabilities. Method: Using a descriptive survey research design, data were collected from 147 participants (women $=57.1 \%$, men $=42.9 \%$ ) on the PEJI survey instrument. Results: Principal component analysis resulted in salient loadings on three dimensions consistent with prior study using the PEJI and explained $57 \%$ of the variance for measuring judgments about: Inclusion versus Exclusion, Acceptance of Students with Disabilities, and Perceived Training Needs. Conclusions: The overall results confirm validity of the PEJI survey consistent with prior study on this measure. The strong magnitude of values indicates that each of the subscales measures separate dimensions of judgments (attitudes). Implications for future use, we recommend reporting individual scale scores rather than a total PEJI score.
\end{abstract}

Keywords: attitudes; physical education; inclusion; disability

\section{Introduction}

Inclusion has become a global phenomenon (Hodge et al., 2009; O’Brien, Kudláček, \& Howe, 2009; Son, Hodge, Chun, \& Kozub, 2012). In broad terms it means students with disabilities are educated together with their same-age schoolmates without disabilities in general education programs, including physical education settings (Hodge, Sato, Mukoyama, \& Kozub, 2013). More specifically, inclusive ideology also means the inclusion of all, "regardless of race, ethnicity, disability, gender, sexual orientation, language, socio-economic status, and any other aspect of an individual's identity that might be perceived as different" (Polat, 2010, p. 51). For example in Brazil the ideology of inclusive education extends beyond students with disabilities to include also students from poor families and impoverished communities who may or may not have disabilities (Chakraborti-Ghosh, Orellana, \& Jones, 2014).

In Brazil, the integration of children with physical or intellectual disabilities into state schools is a constitutional right. Children with or without disabilities enrolled in states schools, attend the school closest to their resident community. The provision of special needs education is the responsibility of the Brazilian Ministry of Education, the state, and of some municipalities (AngloINFO São Paulo, 2014). Nonetheless inclusive educational programming does not always occur in Brazil (Ferreira, 2003; Watson, 2003). Most students with disabilities are taught in separate classes or special schools where there is little or no chance for meaningful interaction with schoolmates without disabilities 
(International Disability Rights Monitor, 2004). Mostly those students with physical disabilities and intellectual disabilities attend segregated schools in Brazil (AngloINFO São Paulo, 2014). Over the past decade, inclusive ideology has gained momentum and consequently students with disabilities are increasingly more likely to attend schools with same-age peers without disabilities in the future (Ferreira, 2003).

The rights of individuals with disabilities are protected under Brazil's Federal Constitution of 1988 and such laws as Federal Law 7853 enacted on 24 October 1989, explicitly protects the rights of individuals with disabilities; and Federal Law 10436, enacted on 24 April 2002 and recognizes Brazilian Sign Language (Libras) as a legal means of communication and expression (International Disability Rights Monitor, 2004). The passage of such laws will continue to increase the probability that Brazilian physical education teachers will have students with disabilities in their classes. In particular, Federal Law 7853/89 supports integrated (inclusive) classes. Under this law, placement (e.g., to attend regular or special/segregated schools) and program decisions about students with disabilities are under the authority of administrators of schools, departments of education, and parents across Brazil's 26 states, federal district (where Brasília, the capital city, is located), and thousands of municipalities (Watson, 2013). Municipalities are administrative divisions of the 26 Brazilian states and there are some 5,570 municipalities. In addition, the Brazilian government enacted the Law of Directives and Bases for National Education in 1996 (Ferreira, 2003). This law established special education as basic education "offered preferably in the regular teaching network for learners who have special needs" (Ferreira, 2003, p. 5). Ferreira (2003) declares that many laws have been approved in Brazil that guarantee, among other rights, the right of all persons to education including laws which support the education of students with disabilities.

Inclusive education is progressing slowly in Brazil. This means in the future students with and without disabilities will more likely be educated together than in past years. The research base indicates that inclusive classes are typified with trivial or no interactions between students with and without disabilities and the classes have few, if any, supports and needed accommodations arranged to promote the success of students with disabilities. In previous research, Brazilian physical education teachers' expressed hesitancy about teaching students with disabilities and contend that they were not sufficiently prepared to do so (Nascimento, Rodrigues, Grillo, \& Merida, 2007).

Nascimento et al. (2007) surveyed teachers in Brazil who had worked with students with disabilities in physical education. They found the teachers had not received adequate professional preparation for working with students with disabilities. Likewise, Zanandrea and Rizzo (1998) evaluated the attitudes of physical education teachers with respect to emotional behavior disorders, learning disabilities, mild cognitive impairments, and orthopedic impairments. They reported that teachers of physical education in Brazil were mostly ambivalent about teaching students with various disabilities (Zanadrea \& Rizzo, 1998). It appears that teachers are not and do not feel adequately prepared to teach students with disabilities in their general education programs (Chakraborti-Ghosh et al., 2014; Ferreira, 2003). Predictably, however, the shifting educational dynamic in Brazil means that physical education teacher candidates and in-service teachers, more so now than ever, must receive appropriate professional preparation and development to teach students with disabilities effectively.

Zanandrea and Rizzo (1998), and more recently Gutierres Filho, Monteiro, Silva, and Hodge (2013) have drawn attention to the attitudes and professional preparation of physical education teachers in Brazil in regards to teaching students with disabilities. Notwithstanding those two empirical studies (Gutierres Filho et al., 2013; Zanandrea \& Rizzo, 1998), available information pertaining to the attitudes of Brazilian physical education teachers about teaching students with disabilities is limited. Rationally, scholars argue that determining, analyzing, and theorizing about the attitudes of physical education teachers is important in the preparation and professional development of these teachers (Hodge et al., 2013; Kowalski \& Rizzo, 1996; Rizzo \& Kirkendall, 1995; Sato, Hodge, Murata, \& Maeda, 2007). It is therefore important to extend the research base using valid and reliable measures. The Physical Educators' Judgments about Inclusion scale (Hodge, Murata, \& Kozub, 2002) is such an instrument and has been used globally with both pre-service and in-service physical education teachers in analyzing their attitudes regarding the ideology of inclusion and teaching students with disabilities (Hodge et al., 2009; Hodge et al., 2013; Son et al., 2012). The purpose of this current study was to examine the underlying dimensions of the Physical Educators' Judgments about Inclusion (Brazilian-version of the PEJI) scale following translation procedures that converted the existing measure to Portuguese. To that end, after approval was granted from the researchers' institutional review board, the study was initiated and data were collected and analyzed. 


\section{Method}

\subsection{Participants and Research Site}

Participants were physical education professionals sampled from individuals who participated in a two-day adapted physical activity professional development workshop held in the capital city of Brasília, Brazil. Specifically 147 usable pretest surveys were completed. This convenience sample was comprised of 84 women $(57.1 \%)$ and 63 men (42.9\%). All of the participants were Postuguese-speaking native Brazilians. The participants' age range was 19 to 55 years (mean age $=37.3$ years old).

Most participants $(n=110,74.8 \%)$ held a post-bachelorate teaching certificate in physical education and $18(12.2 \%)$ held a bachelorate degree in physical education. Eleven (7.5\%) participants were undergraduate physical education majors. In addition, $5(3.4 \%)$ participants held a master's degree and $3(2.0 \%)$ held doctoral degrees.

Most $(n=130,88.4 \%)$ participants had experience teaching physical education with a range of 1 to 34 years of experience $($ mean $=11.4$ years). There were however $17(11.6 \%)$ participants who had no experience teaching physical education. Further most $(n=119,81 \%)$ participants had experience teaching students with disabilities in physical education with a range of 1 to 30 years of experience (mean $=6.4$ years). There were $28(19 \%)$ participants who had no experience teaching students with disabilities.

\subsection{Research Design and Instrumentation}

The research method was a descriptive survey (Fraenkel \& Wallen, 1990). This survey approach facilitated collecting and analyzing data from the physical education professionals in a manageable and timely manner. In brief, survey data were gathered using the PEJI scale with an accompanying demographic questionnaire (Hodge et al., 2002). Before the data collection process was initiated, the PEJI survey scale and demographic questionnaire were translated from the original English version to the participants' native Portuguese language using a cross-cultural language translation technique (Banville, Desrosiers, \& Genet-Volet, 2000). This process is summarized briefly next.

Four native Portuguese-speaking Brazilian translators (A [data collector], B, C, and D) were three bilingual faculty in adapted physical education (APE) programs at universities in Brazil and a bilingual graduate student in a special education graduate program at a university in the United States (U.S.). All translators were fluent in both English and Portuguese languages. First, two translators (A and B) at separate universities individually translated the original English version of the PEJI survey and demographic questionnaire into Portuguese. Later through e-mail correspondence they compared their versions and discussed any differences to arrive at an agreement. They then edited the instrument as deemed necessary for proper vocabulary, grammar and syntax of the Portuguese language. The Portuguese version from this process was sent to a bilingual APE faculty member (Translator C) also in Brazil and to a special education doctoral student (Translator D) at a university in the U.S., who translated the instruments back into English. In the second step, a committee composed of six persons including the four bilingual translators and two APE faculty members in the U.S. were asked, via e-mail correspondence, to critique (evaluate) the instrument. The committee affirmed that the survey instrument's items were the same as the original PEJI while respecting Portuguese syntax for all items on the instrument. In the next step, the instrument was piloted with a bilingual Brazilian doctoral student at a university in the U.S. She answered both the Brazilian (i.e., Portuguese language) and English versions of the instrument successively. The Portuguese-speaking Brazilian translators and doctoral student confirmed the accuracy of the instrument's content to measure what it purports to measure in both Portuguese and English versions. In summary, all of the aforementioned steps were important aspects of the language translation and validation process that allowed us to verify cultural and language relevance of the survey.

Subsequent to the language translation process, we used the PEJI survey as designed to gather data on the physical education professionals' judgments about the inclusion of students with disabilities in physical education. The PEJI survey assesses participants' judgments about: (a) inclusion versus exclusion, (b) acceptance of students with disabilities, and (c) perceived training needs (Hodge et al., 2002). Hodge and colleagues explained that the items in the original PEJI survey were developed through a review of the literature, focus group input, expert review, and pilot testing. Content validity evidence was established with the use of focus group input, and later confirmed by a panel of experts. Next, construct validity was established statistically through psychometric procedures, which resulted in a survey comprising three subscales: Judgments about Inclusion versus Exclusion, Judgments about Acceptance of Students with Disabilities, and Judgments about Perceived Training Needs (Hodge et al., 2002).

\section{Data Collection and Analysis Procedures}

In the current study, the data collector was a native and resident of Brazil. He was also an APE professional fluent in 
his native Portuguese language. However, the data collector was not one of the instructors of the professional development workshop held in Brasília, Brazil. Prior to data collection, all those attending the workshop were asked by the data collector to read and sign informed consent forms for participating in this study. They were assured that participation was voluntary and that if they elected not to participate it would not affect their workshop participation in any way. Informed consent was received from each of the participants by the data collector at the start of the professional development workshop. Confidentiality was ensured as the data were reported in aggregate.

More specifically, the study's attitude survey with accompanying demographic questionnaire was distributed and collected by the data collector from each participant before the first session started on Day 1 of the professional development workshop. The number of participants was determined by the number of completed surveys from a total of 147 individuals who attended the workshop and volunteered to participate (and provided usable responses).

The PEJI was administered with an attached cover sheet that gave the participants general instructions for completing the instrument and a definition of inclusion. On the PEJI cover sheet, inclusion was defined as: an approach that supports the placement of all students with different abilities and disabilities (mild to severe) into physical education classes with schoolmates in their community schools. A definition sheet describing the various disability types mentioned in the PEJI also accompanied the survey. The participants were asked to circle the response, for each statement, that best described their judgment about that statement. Their responses on the PEJI were averaged based on its 5-point scoring scale of strongly disagree $=1$ to strongly agree $=5$. Scoring on negatively phrased items was reversed. No names were requested on papers, and participants were assured that their responses were anonymous. No time limit was imposed, but completion of the PEJI scale generally took less than 15 minutes.

The researchers used well-established guidelines in analyzing the properties of the PEJI survey (Antonak \& Livneh, 1988; Stevens, 1992). The analyses included descriptive statistics and checking of statistical assumptions. An initial correlation matrix was used to determine whether confirmatory factor analysis would be useful in extracting and naming underlying dimensions of the PEJI. Underlying dimensions were explored as was the case in Hodge and colleagues (2002); however, a maximum-likelihood procedure was used to confirm the three-factor model of the PEJI from the current dataset. In this analysis, as in the earlier studies, both orthogonal and oblique rotations resulted in a three-factor model with all items loading consistently with the results of Hodge and colleagues (Hodge et al., 2002; Hodge et al., 2013; Son et al., 2013). The decision to present findings from the orthogonal rotation was made based on low correlations between subscales (Stevens, 1992). All items loaded significantly based on sample size as discussed in Hair, Anderson, Tatham, and Black (1995). Fifteen items met the minimal criterion of magnitude of 0.30 , with 14 items meeting the $>0.40$ criterion of importance as discussed in Vincent (1995). Further, there was consistency with the dimensions identified in the original English version of the PEJI survey, leading to a decision to retain all 16 of the items (Table 1). Cronbach's (1951) alpha procedure resulted in encouraging estimates for two of the PEJI subscales.

\subsection{PEJI Brazilian-version}

For the Brazilian-version of the scale, our decision to analyze the three variables extracted using Principal Components resulted from determining the presence of significant correlations between items within subscales and underlying PEJI dimensions consistent with previous studies (Hodge et al., 2002; Hodge et al., 2013; Son et al., 2013). Communality statistics ranged from .16 to .82 for the 16 items. Further examination of Eigenvalues and a scree plot reveal downward slope that levels off after three factors are extracted. The salient loadings found in Table 1 ranging from -.39- .88 provides validity evidence for the 3-component model identified in Hodge et al. (2002). 
Table 1. Scale Factor Loadings Derived from Principal Components Analysis

\begin{tabular}{|c|c|c|c|}
\hline Item \# & $\begin{array}{c}\text { Judgments about } \\
\text { acceptance of students } \\
\text { with disabilities }\end{array}$ & $\begin{array}{c}\text { Judgments about } \\
\text { perceived training needs }\end{array}$ & $\begin{array}{c}\text { Judgments about } \\
\text { inclusion versus } \\
\text { exclusion }\end{array}$ \\
\hline 6 & .88 & & \\
\hline 9 & .87 & & \\
\hline 7 & .84 & & \\
\hline 10 & .83 & & \\
\hline 8 & .79 & & \\
\hline 15 & & .82 & \\
\hline 14 & & .80 & \\
\hline 13 & & .73 & \\
\hline 16 & & .72 & \\
\hline 12 & & .62 & \\
\hline 11 & & .61 & \\
\hline 3 & & & .67 \\
\hline 2 & & & .66 \\
\hline 5 & & & .64 \\
\hline 4 & & & .46 \\
\hline 1 & & & -.39 \\
\hline Eigenvalue & 4.35 & 3.22 & 1.56 \\
\hline$\%$ of Variance & 27.16 & 20.15 & 9.74 \\
\hline $\begin{array}{l}\text { Cumulative } \% \text { of } \\
\text { explained variance }\end{array}$ & & & \\
\hline
\end{tabular}

Note. The resulting component loadings resulted from varimax rotation.

Table 2 presents psychometric indices (i.e., $M, S D$, SEM, skewness, kurtosis, scores range, and alpha) for the Brazilian version of the PEJI and its three subscales.

Table 2. Psychometric Indices for the Final PEJI and the Subscales

\begin{tabular}{lccc}
\hline \multicolumn{3}{c}{ Subscale Score } \\
\hline & $\begin{array}{c}\text { Judgments about inclusion } \\
\text { versus exclusion }\end{array}$ & $\begin{array}{c}\text { Judgments about } \\
\text { acceptance of students } \\
\text { with disabilities }{ }^{1}\end{array}$ & $\begin{array}{c}\text { Judgments about perceived } \\
\text { training needs }^{2}\end{array}$ \\
\hline$M$ & 2.94 & 4.30 & 4.28 \\
$S D$ & .62 & .60 & .54 \\
SEM & .05 & .05 & .05 \\
Skewness & .28 & -.85 & -.20 \\
Kurtosis & 4.50 & .67 & -.98 \\
Minimum & 1.20 & 2.40 & 3.17 \\
Maximum & 5.00 & 5 & 5 \\
Alpha & .34 & .89 & .80 \\
\hline
\end{tabular}

Note. Minimum and maximum values represent ranges for mean values for the two ${ }^{1}$ five and one ${ }^{2}$ six $_{\text {item scales. }}$

Total subscale internal consistency estimates (Cronbach, 1951) resulted in alpha values of .34 for Judgments about Inclusion versus Exclusion, 95 for Judgments about Acceptance of Students with Disabilities, and .80 for Judgments about Perceived Training Needs (Table 2). Table 3 has descriptive statistics on the 16 items and includes item phrasing in relation to scoring (positive or negative). 
Table 3. PEJI Subscales Items, Item Phrasing, and Descriptive Results

\begin{tabular}{|c|c|c|c|c|}
\hline Item & Items Appearing on Subscales & Phrasing & $M$ & $S D$ \\
\hline \multicolumn{5}{|c|}{ Subscale 1. Judgments about Inclusion versus Exclusion } \\
\hline 1 & All students with disabilities should be taught in regular PE classes. & + & 2.92 & 1.031 \\
\hline 2 & Inclusion is an idealistic philosophy that will not work in regular PE. & - & 2.70 & 1.17 \\
\hline 3 & Students with severe disabilities should be taught in separate classes. & - & 2.80 & 1.12 \\
\hline 4 & $\begin{array}{l}\text { Students with severe disabilities always need a one-on-one ratio to } \\
\text { successfully take part in inclusive physical education activities. }\end{array}$ & - & 3.44 & 1.18 \\
\hline 5 & $\begin{array}{l}\text { Given the range of disabilities that exist, it is unrealistic to expect a } \\
\text { regular PE teacher to teach all students who have disabilities in their } \\
\text { classes. }\end{array}$ & - & 2.82 & 1.17 \\
\hline \multicolumn{5}{|c|}{ Subscale 2. Judgments about Acceptance of Students with Disabilities } \\
\hline 6 & $\begin{array}{l}\text { I would readily accept teaching a student who is hard-of-hearing in my } \\
\text { PE classes. }\end{array}$ & + & 4.35 & .80 \\
\hline 7 & $\begin{array}{l}\text { I would readily accept teaching a student with a visual impairment in my } \\
\text { PE classes. }\end{array}$ & + & 4.27 & .84 \\
\hline 8 & $\begin{array}{l}\text { I would readily accept teaching a student with a learning disability in my } \\
\text { PE classes. }\end{array}$ & + & 4.49 & .57 \\
\hline 9 & $\begin{array}{l}\text { I would readily accept teaching a student with a physical disability (e.g., } \\
\text { a student who uses a wheelchair or crutches) in my PE classes. }\end{array}$ & + & 4.41 & .77 \\
\hline 10 & I would readily accept teaching a student with an intellectual disability. & + & 4.45 & .58 \\
\hline \multicolumn{5}{|c|}{ Subscale 3. Judgments about Perceived Training Needs } \\
\hline 11 & $\begin{array}{l}\text { To be prepared to teach students with disabilities I need course work that } \\
\text { gives me knowledge about disabilities from mild to severe. }\end{array}$ & + & 4.56 & .66 \\
\hline 12 & $\begin{array}{l}\text { To be prepared to teach students with mild disabilities I need exposure } \\
\text { (e.g., direct contact) to students who have mild disabilities during my } \\
\text { training. }\end{array}$ & + & 4.30 & .80 \\
\hline 13 & $\begin{array}{l}\text { To be prepared to teach students with severe disabilities I need exposure } \\
\text { (e.g., direct contact experiences) to students who have severe } \\
\text { disabilities. }\end{array}$ & + & 4.39 & .71 \\
\hline 14 & $\begin{array}{l}\text { To be prepared to teach students with mild to severe disabilities it is } \\
\text { important that I receive training on activities that includes ideas on } \\
\text { lesson planning for a variety of ability levels. }\end{array}$ & + & 4.46 & .64 \\
\hline 15 & $\begin{array}{l}\text { To be prepared to teach students with mild to severe disabilities I need } \\
\text { training in behavioral management strategies and conflict resolution } \\
\text { beyond what is necessary to teach students without disabilities. }\end{array}$ & + & 4.04 & .87 \\
\hline 16 & $\begin{array}{l}\text { To be prepared to teach students with various disabilities I need to assist } \\
\text { effective regular PE teacher actually teaching students with disabilities. }\end{array}$ & + & 3.94 & .89 \\
\hline
\end{tabular}

\section{Discussion and Implications}

The overarching aim of this study was to analyze the underlying dimensions of the Brazilian-version of the PEJI scale following translation procedures that converted the existing measure to Portuguese for future analysis of Brazilian physical education professionals' attitudes about inclusion and teaching students with disabilities.

\subsection{A Discussion about the PEJI Brazilian Version}

Supported by the interpretable factors that emerged, specific to the Brazilian version of the PEJI construct, validity evidence is presented by confirming a three-factor model from responses of Brazilian physical education professionals. These results are consistent with previous psychometric results for the scale (Hodge et al., 2002; Hodge et al., 2013; Son et al., 2012). It was reaffirmed that Judgments about Inclusion versus Exclusion captures key judgments that comprise the inclusion philosophy. Judgments about Acceptance of Students with Disabilities clearly measures acceptance of students with various disabilities. The dimension, Judgments about Perceived Training Needs captures physical education professionals' perceived need for additional professional development in teaching 
students with disabilities. Using these three dimensions, the responses explained $57 \%$ of the variance in the original 16 items and reaffirmed the hypothesized model, thus lending further support to previous psychometric results (Hodge et al., 2002; Hodge et al., 2013; Son et al., 2012). Hodge and colleagues (2002) used a less stringent total variance analysis to identify underlying dimensions in the English version of the scale. The current solution is consistent with the previous studies cited by Hodge et al. (2013), and Son et al. (2012). These studies provide estimates of validity for the three subscale measures of teachers' and teacher candidates' judgments about inclusion and support the use of the Brazilian version of the scale.

It is unclear why the first subscale, Inclusion versus Exclusion, resulted in a modest alpha estimate from these data. Deletion of the first item provides a more encouraging estimate of reliability for this subscale but eliminates an important judgmental inference important in these data. The notion of whether or not a child with a disability can be included is a staple of this type judgement research and therefore we decided to not remove the item. Perhaps more study is needed along with the addition of more items that examine this important notion of if inclusion is possible in general physical education in Brazil. The translational dynamics at play in Brazil from special or segregated schools to integrated and inclusive schools, and even curricular offerings may have influenced the teachers' judgements on this item.

Of importance, Cronbach's (1951) alpha estimates taken collectively for the PEJI are encouraging and lend support to reliability for at least two of the subscales and for the remaining subscale when experience level is considered. The strong magnitude of values indicates that each of the subscales measures separate dimensions of attitudes (judgments). In future studies, we recommend reporting individual scale scores rather than a total PEJI score (Hodge et al., 2002; Hodge et al., 2013; Son et al., 2012).

\subsection{Limitations of the Study}

The overall findings of this study are vulnerable because groups were not randomly selected and all variables that might affect outcomes could not be controlled. However, ANOVA tests indicated groups to be equated on key variables: gender and previous experience teaching students with disabilities. It must also be acknowledged that the participants may have marked what they believed were socially acceptable responses on the survey scale (Thomas \& Nelson, 2001). This is a problem inherent in self-report surveys. Researchers depend on the truthfulness of the participants' responses. Lastly, the use of a non-randomized sample does limit this study in terms of statistical generalization of results. To reiterate however, supported by the interpretable constructs that emerged, specific to the Brazilian version of the PEJI construct, validity evidence is presented by reaffirming a three-dimensional model from responses of Portuguese-speaking Brazilian physical education professionals.

\section{References}

AngloINFO São Paulo. (2014). Special needs education in Brazil. São Paulo (Brazil). Retrieved from http://saopaulo.angloinfo.com/information/family/schooling-education/special-needs/.

Antonak, R. F., \& Livneh, H. (1988). The measurement of attitudes toward people with disabilities: Methods, psychometrics and scales. Springfield, IL: Charles C. Thomas.

Banville, D., Desrosiers, P., \& Genet-Volet, Y. (2000). Translating questionnaires and inventories using a cross-cultural translation technique. Journal of Teaching in Physical Education, 19, 374-387.

Chakraborti-Ghosh, S., Orellana, K. M., \& Jones, J. (2014). A cross-cultural comparison of teachers' perspectives on inclusive education through a study abroad program in Brazil and in the US. International Journal of Special Education, 29(1), 4-13.

Cronbach, L. J. (1951). Coefficient alpha and the internal structure of tests. Psychometrika, 16, 297-334. http://dx.doi.org/10.1007/BF02310555

Ferreira, W. B. (2003). Public policies. Retrieved from www.cnotinfor.pt/inclusiva/report_politicas_publicas_en.html

Fraenkel, J. R., \& Wallen, N. E. (1990). How to design and evaluate research in education. San Francisco: McGraw-Hill.

Gutierres Filho, P. J. B, Monteiro, M. D. A. F., Silva, R. da, \& Hodge, S. R. (2013). Instructors' application of the theory of planned behavior in teaching undergraduate physical education courses. Educational Research and Reviews, 8(10), 589-595. 
Hair, Jr. J. F., Anderson, R. E., Tatham, R. L., \& Black, W. C. (1995). Multivariate data analysis with readings (4th ed.). Upper Saddle River, NJ: Prentice-Hall.

Hodge, S. R., Ammah, J. O. A., Casebolt, K. M., LaMaster, K., Hersman, B. L., Samalot-Rivera, A., \& Sato, T. (2009). A diversity of voices: Physical education teachers' beliefs on teaching students with disabilities. International Journal of Disability, Development and Education, 56(4), 401-419. http://dx.doi.org/10.1080/10349120903306756

Hodge, S. R., Murata, N. M., \& Kozub, F. (2002). Physical educators' judgments about inclusion: a new instrument for pre-service teachers. Adapted Physical Activity Quarterly, 19, 435-452.

Hodge, S. R., Sato, T., Mukoyama, T., \& Kozub, F. M. (2013). Development of the physical educators' judgments about inclusion instrument for Japanese physical education majors and an analysis of their judgments. International Journal of Disability, Development and Education, 60(4), 332-346. http://dx.doi.org/10.1080/1034912X.2013.846468

International Disability Rights Monitor (IDRM). (2004). Brazil-2004 IDRM country report. Retrieved from http://www.ideanet.org/content.cfm?id=535D

Kowalski, E. M., \& Rizzo, T. L. (1996). Factors influencing preservice student attitudes toward individuals with disabilities. Adapted Physical Activity Quarterly, 13, 180-196.

MINITAB Statistical Software. (2000). MINITAB Release 13 for windows. State College, PA: Minitab Inc.

Nascimento, K. P., Rodrigues, G. M., Grillo, D. E., \& Merida, M. (2007). A formação do professor de educação física na atuação profissional inclusiva. [The professionalization of physical education teacher and its inclusive professional activity]. Revista Mackenzie de Educação Física e Esporte, 6(3), 53-58.

O’Brien, D., Kudláček, M., \& Howe, P. D. (2009). A contemporary review of English language literature on inclusion of students with disabilities in physical education: A European perspective. European Journal of Adapted Physical Activity, 2(1), 46-61.

Polat, F. (2010). Inclusion in education: A step towards social justice. International Journal of Educational Development, 31(2011), 50-58.

Rizzo, T. L., \& Kirkendall, D. R. (1995). Teaching students with mild disabilities: What affects attitudes of future physical educators? Adapted Physical Activity Quarterly, 12, 205-216.

Sato, T., Hodge, S. R., Murata, N. M., \& Maeda, J. K. (2007). Japanese physical education teachers' beliefs about teaching students with disabilities. Sport, Education and Society, 12, 211-230. http://dx.doi.org/10.1080/13573320701287536.

Son, Y., Hodge, S. R., Chun, H., \& Kozub, F. M. (2012). South Korean undergraduate collegians' beliefs about inclusion and teaching students with disabilities. International Journal of Human Movement Science, 6(1), 153-174.

Stevens, J. (1992). Applied multivariate statistics for the social sciences ( $2^{\text {nd }}$ ed.). Hillsdale, NJ: Lawrence Erlbaum Associates.

Thomas, J. R., \& Nelson, J. K. (2001). Research methods in physical activity (4th ed.). Champaign, IL: Human Kinetics.

Vincent, W. J. (1995). Statistics in kinesiology. Champaign, IL: Human Kinetics.

Watson, S. M. (2013). Lessons from Brazil: Separate and unequal educational systems. Preventing School Failure, 57(3), 148-151. http://dx.doi.org/10.1080/1045988X.2013.785924

Zanandrea, M., \& Rizzo, T. (1998). Attitudes of undergraduate physical education majors in Brazil toward teaching students with disabilities. Perceptual \& Motor Skills, 86, 699-706. http://dx.doi.org/10.2466/pms.1998.86.2.699 